Article

\title{
The Urban Digital Platform: Instances from Milan and Amsterdam
}

\author{
Letizia Chiappini ${ }^{1,2}$ \\ ${ }^{1}$ Department of Geography, Urban Planning and International Development, University of Amsterdam, \\ 1001 NC Amsterdam, The Netherlands; E-Mail: I.chiappini@uva.nl \\ 2 Department of Sociology and Social Research, University of Milan-Bicocca, 20126 Milan, Italy
}

Submitted: 30 June 2020 | Accepted: 11 September 2020 | Published: 15 December 2020

\begin{abstract}
The article interrogates the concept of the urban in relation to digital platforms designed for citizen-based initiatives and local projects. We must broaden our scope as urban scholars to include this vast undergrowth of 'other' platforms and study how they intersect with the social and material fabric of cities. Drawing from media and internet studies, urban sociology, and digital geography, I introduce the novel concept of 'urban digital platform' (UDP). I do so theoretically by using a digital geography body of work and the level of abstractness proposed by Bratton (2016), in 'the stack,' which are entry points to define any kind of digital platform. While global and for-profit digital platforms exploit density, size, and diversity, extracting resources into a data-driven form of governance and computational production of space. UDPs benefit from the urban as a front to (re)organise citizen-based, mutual-aid initiatives, and solidarity actions. The core of the UDP concept lies in the ambiguity of the role of the urban government, media literacy, and techno-biases as basic requirements for citizens to access the platform, its services, and goods. Those claims are supported by instances and empirical findings of two analysed platforms in Milan and Amsterdam.
\end{abstract}

\section{Keywords}

city layer; digital geography; platform urbanism; urban digital platform

\section{Issue}

This article is part of the issue "Digital Geographies and the City" edited by Wen Lin (Newcastle University, UK).

(C) 2020 by the author; licensee Cogitatio (Lisbon, Portugal). This article is licensed under a Creative Commons Attribution 4.0 International License (CC BY).

\section{Introduction}

Digital platforms are affecting cities in myriad ways; they impact both interurban connectivity and intraurban functionality. The existing literature on digital platforms defines them very broadly, namely as any digitally hosted instrument to share or enable the exchange of information or services at a global scale. Notions such as 'platform capitalism' (Srnicek, 2017) and the emergent concept in urban studies of 'platform urbanism' (Barns, 2019; Moore \& Scott, 2018) capture one side of the urban transformation that our cities are facing. This one side mainly focuses on the increasingly central role of data, conceived of as a commodity, where digital platforms play a role as global capitalist forces in sourcing data and monetising it (Rose, Raghuram, Watson, \& Wigley, 2020). In the concept of 'platform urbanism,' there is a specific urban character: Platforms that deal with the urban tend to share initiatives, information and knowledge, and be dependent on cities for their data, service, and local networks. At the same time, there is no critical eye on the differentiation between digital platforms that commodify urban resources and another subset of platforms, which digitally-mediate urban experiences, such as citizen-based solidarity initiatives, in which the local state might have a role not only as a regulator but as an active promoter.

There is still little knowledge regarding not-for-profit digital platforms which are designed for public participation, solidarity, and diverse transactions beyond those that are exclusively economic. Public participation and grassroots initiatives vary from civic crowdfunding and complementary welfare platforms (i.e., time-banks) but they also pertain to broader societal effects, such as solidarity, democratic control, and accountability. In particular, during the Covid-19 pandemic crisis, a crucial aspect has emerged. On one side, global digital platforms such as Airbnb and Uber are losing grip in cities; due to the cir- 
cumstances, they are adjusting their business model to circumvent regulatory regimes and suit (again) the market (Richardson, 2019). On the other side, new types of digital platforms are gaining terrain in offering support: mutual-aid and solidarity at a city-level. For instance, the municipality of Amsterdam launched its own digital platform 'We Amsterdam' storing both offline and online civic initiatives to support citizens during the corona crisis (Mos, 2020). Elsewhere, the Milanese municipality opened another round of civic crowdfunding, offering financial support to help vulnerable citizens during the corona outbreak which severely hit Lombardy and Milan. The questions on how digital platforms affect urban geography and governance arrangements, and vice versa, as well as how cities affect digital platforms are not arbitrary within urban studies.

Urban digital platforms (UDPs) are potential ways to (re)organise the social economy, civic initiatives and complementary welfare provision. Besides, UDPs necessitate a revision of the role of the local government as they enable new forms of social organisation as well as new forms of both producing and delivering goods and services. Hence, this article reflects upon urban platforms as an alternative output form of grassroot and entrepreneurial projects, community-oriented practices and collective actions, in which the local state might intervene to prevent or favour a particular kind of urban development and production of urban space (Fisker, Chiappini, Pugalis, \& Bruzzese, 2019). UDPs are an alternative form of escape from the voracious and exploitative global digital platforms. The core of my argument is that certain digital platforms are urban a priori, i.e., platforms for the city, rather than platforms which feed on it: where 'the city' is conceived as an urban commonwealth, not a growth pole. As summarised in Mark Purcell's (2008) Recapturing Democracy and in "Cities for People, Not for Profit," by Brenner, Marcuse, and Mayer (2009), the UDP is a platform for people and not for profit, aiming at recapturing accountability and democratic principles.

In order to lend visibility to, and direct analytical attention toward, a wider diversity of platforms, I introduce an operationalised definition of the UDP. UDPs can be an opportunity for solidarity-based 'urban commonwealth" (Kohn, 2016), reimagining the city as an "innovative form of collective cooperation and collective corporation" (Merrifield, 2014, p. 390). Citizens are not re-cast in the role of consumers but rather as producers of space. Different from smart city projects or platform urbanism in which users are able to participate in mundane tactics and everyday life activities, such as using a bikesharing service, UDPs offer the possibility to (re)create urban commons and generate solidarity and collective actions. Those observations derive from four years of fieldwork in Milan and Amsterdam. The research is a comparative perspective based on a match-pairing of two UDPs which operate in both cities: civic crowdfunding and Commonfare. The methods deployed are most- ly qualitative, such as 20 interviews, participant observations, and mapping of projects within the abovementioned UDPs.

Both platforms represent potential alternatives for local arrangements and citizen engagement, without profiting from the urban or directly exploiting local resources. The UDP term is an attempt to revitalise the importance of the urban as a space of contestation and potential political rearrangements towards alternative production of space, rather than as a space for corporateled digital platforms. The need for the UDP as a new concept is to broaden our scope to contrast the essential motive of platform capitalist firms in the collection of huge masses of data. Large cities and metropolitan areas, and in particular urban centres that have become hegemons in the collective imagination, function as living labs for key companies in western urban economies. For 'the new prophets of capital,' as Nicole Aschoff (2015) has called them in the latest book, global digital platforms tend to present themselves as philanthropic while conducting business in the name of the 'common good' (Rossi, 2019).

In pointing out the significance of the UDP as a separate concept, platform urbanism is conceived of as an emergent condition of the urban and a new field of study in which the concept of the UDP resonates. The proposed operationalised definition of the UDP is to emphasise that is not-for-profit, designed for smallscale and local initiatives in which the type of provision is Peer-to-Peer (P2P; Benkler, 2006), and often requires the intervention of the local state. With a proper conceptualisation of the UDP, critical urban scholars can start to shape social and economic relations in a different way as opposed to reducing our role as researchers to mapping the 'impact' or negative effects of digital platforms. The attempt by Leszczynski $(2020$, p. 189) is indeed "a counter-topographical minor theory of platform urbanism," which explores a more nuanced understanding of politics in platform urbanism that resonates and intersects with the definitional work of UDP presented in this article.

The article is structured as follows: The second section revises the main contribution that digital platforms, from an interdisciplinary perspective within media and internet studies, have made to digital geography. The third addresses the definition of the UDP with particular attention to the two cities analysed, Milan and Amsterdam, in which instances of UDPs are observed. The fourth is a level of abstraction on how the concept of 'the stack,' proposed by Bratton (2016), might engage and enrich the definition of the UDP as a separate analytical category and a gloss to platform urbanism as a new field of research.

\section{From Digital Platforms to Digital Geography}

According to Leszczynski (2017), digital platforms are disrupting what has become established within the 'field' 
of long-standing geographical concerns, pushing for new lines of inquiry. The digital turn in geography has called for scholars to investigate how "geographies are produced through, produced by, and of the digital" (Ash, Kitchin, \& Leszczynski, 2018, p. 25, emphasis in original). However, the epistemological approach from digital geography does not address the diversity of global digital platforms that operate in the urban context (and benefit from the infra density in order to increase extraction of value) versus the local solutions which support citizenbased initiatives and small scale urban projects that are unique to the place and social structure of that particular city.

\subsection{Digital Platforms}

Existing research within internet and digital media studies has generated a rich set of analytical categories on the social implications of digital technologies, including platforms (Pasquale, 2015, 2018). Those analytical categories offer a critical reading of the largely negative social consequences of the various technologies that increasingly shape the digital infrastructures of everyday life (Greenfield, 2017; Hine, 2017; Kitchin \& Dodge, 2011). Digital platforms have multiple shapes: corporate, commercial, non-profit, crowd-sourced, on-demand, all bringing in a multitude of activities, services, exchanges, forums, infrastructures, and ordinary practice (Langley \& Leyshon, 2017).

As Tarleton Gillespie (2010) argued, the term 'platform' clearly does discursive work for commercial entities such as Facebook, Amazon, and Google. It allows them to be variably (and often ambiguously) described and imagined as technical platforms, platforms for expression, or platforms of entrepreneurial opportunity. Following up on this, Gillespie (2018) described at length how platforms actively curate, choose, and select content. Grounded in media and communication studies, Gillespie (2018) blends a political economy framework to show how technologies shape conditions of public discourse and public values, with a hint of the normative vision in the analysis of policies that deal with digital platforms. Within this field, one of the attempts to define any kind of digital platform is proposed by Gillespie (2018, p. 207):
Platforms constitute a fundamentally new information configuration, materially, institutionally, financially, and socially. While they echo and extend traditional forms of communication and exchange, they do so by being, like computers themselves 'universal machines' for many different kinds of information exchange...moderation, far from being occasional or ancillary, is in fact an essential, constant, and definitional part of what platforms do. I mean this literally: moderation is the essence of platforms; it is the commodity they offer.

The current debate on digital platforms usually refers to hyped discourses on the 'sharing economy' (cf. Botsman \& Rogers, 2010; Frenken \& Schor, 2017; Richardson, 2019) and 'gig economy' (Woodcock \& Graham, 2019), as well as key firms in the sector such as Airbnb, Uber, and Deliveroo. According to van Doorn (2019, p. 1), digital platforms such as Airbnb should be understood as "new urban institutions transforming relations between market, state, and civil society." As van Dijck, Poell, and de Waal (2018) indicate, digital platforms are indeed reshuffling public and private values, as well as democratic processes. Schor (2016) insists on the fact that the type of provider and the orientation of the platform is crucial to understand their effect and impact on society. Table 1 shows what is widely discussed is the type of provider and the kind of platform orientation; some of the well-known platforms are P2P and Business-to-Peer (B2P). Although Airbnb, Uber, and Deliveroo are $\mathrm{P} 2 \mathrm{P}$, their corporative and entrepreneurial character is confirmed by the type of platform orientation which is clearly for-profit in which the value is extracted by the production of relational transactions. Yet, the relationship with the city is overlooked and does not help to sharpen the distinction between different digital platforms.

Anyone seeking commonalities between all these entities faces a proliferation of terms to define them, most of them loosely revolving around the idea of digital platforms serving as intermediaries. Unlike ordinary websites and apps, platforms operate at a meta-level because they bring together different players in which the relations between the parties becomes the service itself (Karatzogianni \& Matthews, 2018). The primary function of this structure is to enable the formation

Table 1. Platform orientation and type of provider. Source: Author, after Schor (2016).

\begin{tabular}{|c|c|c|c|}
\hline & & \multicolumn{2}{|c|}{ Type of Provider } \\
\hline & & $\mathrm{P} 2 \mathrm{P}$ & $\mathrm{B} 2 \mathrm{P}$ \\
\hline \multirow[t]{6}{*}{ Platform Orientation } & Non-profit & Time Republick (time banks) & Platform Coops (Smart.Be) \\
\hline & & CommonFare & \\
\hline & & Civic Crowdfunding & \\
\hline & For-Profit & Airbnb & SnappCar \\
\hline & & Uber & ShareToGo \\
\hline & & Deliveroo & \\
\hline
\end{tabular}


of networks and ways of measuring and monetising activity across these networks from which value is extracted, resulting in the so-called 'platform capitalism' (Srnicek, 2017). This may result in uneven geographies in which platforms reproduce, deepen or transform existing urban inequalities (Törnberg \& Chiappini, 2020).

Most of the global digital platforms mentioned have a significant urban dimension (Artioli, 2018). Without cities and users/dwellers there is nothing to deliver, nobody to accommodate, and no-one to pick up and drive around the city. Whereas the operations of platforms such as Airbnb, Uber, and Foodora are by no means limited to cities, their business models are entirely dependent on dense urban settings: there is no profit without cities to operate in. However, it is not enough to claim that digital platforms might be new urban institutions, structures, and infrastructures. This argumentation ostensibly aligns with Scott and Storper's (2015, p. 12) more general argument that:

A viable urban theory should enable us to distinguish between the dynamics of social life that are intrinsically urban from those that are more properly seen as lying outside the strict sphere of the urban, even when they can be detected as a matter of empirical occurrence inside cities.

As a general statement, however, this espouses an urban essentialism in which the two scholars conflate the 'urban' with the 'city,' or rather reduce it to their narrow conception of the city.

What is needed, in order to understand what is inherently urban in digital platforms, is to retain a distinction between 'urban' and 'city.' For instance, Angelo and Wachsmuth $(2015$, p. 19) write: "Which is it? Urbanization or the city: One is a process, the other a site that is one (but not the only) outcome of that process. Surely they are not the same thing." It is then still valid that cities are large and dense urban settlementsoutcomes of urban processes-and socially heterogeneous places. All digital platforms are entangled in the process of urbanisation, but not all of them can be said to be in, of, and for the city. This is also the reason why, in the next session, I explain which are the significant analytical reasons for practising this kind of sharp distinction when it comes to my study of UDPs. It is analogous to Gramsci's claim that the state and civil society cannot be separated, only to then go ahead and separate them anyway, because he finds it analytically necessary: a reluctant conceptualisation (Gramsci, 1994). To do so, I propose an operationalised definition of UDPs which are parts of an urban commonwealth whereas global digital platforms are part of an urban growth machine. Conceived this way, the UDPs don't even have to be strictly non-profit as long as they can be seen to contribute to the production of cities for and by people.

Arguably, Airbnb, Uber, and Foodora are inherently spatial in their manifestations since those platforms operate in different urban markets, such as mobility, accommodation, delivery. Any digital platforms that intermingle with the city need an existing urban community (network effect), which eventually plays out as a 'community marketplace' where social interaction is commodified through the platform in an economic transaction (Celata, Hendrickson, \& Sanna, 2017). Digital platforms facilitate any type of socioeconomic activity and mediate relations, as well as organise the exchange of services, goods, capital, and labour (Artioli, 2018). However, what I observe is that in the current literature there is a larger population of corporate global digital platforms and a subset of UDPs. Hence, relatively little attention has been given to 'other' digital platforms oriented to non-profit, cooperative and bottom-up practices, social economy, and common goods, such as platforms for citizen participation, grassroot mobilisation, and urban regeneration interventions.

At first sight, one can claim that bike or car-sharing services are also urban per se. However, most of the mobility firms who provide such service are third parties or cloud platforms which collect an enormous amount of data (see the example of the Chinese company for bike-sharing, Glovo). To sharpen up the definition of UDP, I observe that they relate also to the role of the local state apparatus and material and immaterial resources which are deployed within the platform, such as local knowledge, funds, and citizens.

\subsection{Geography and Its Digital Turn}

The main contribution to digital platforms within media and internet studies of the city layer highlights the question of the relationship between digital networks and territory. In political geography terms, the tension between territories and networks has been widely explored, in particular in relation to state power and sovereignty (cf. Brenner, 2004; Kitchin, 2019). As Rodgers and Moore (2018) claim, "[sovereignty] is neither generalized nor homogeneous: it manifests in geographically uneven intensities and extents." In the same vein, Painter (2010, p. 1090) analyses this tension, claiming that "territory and network are not, as is often assumed, incommensurable and rival principles of spatial organisation, but are intimately connected." Since they are intimately connected, digital platforms rely on the territory and its resources, along with the user-network that uses those resources. In short, users are the active components to make these platforms work within the city layer.

Digital networks, territory, augmentation of space, and diversity are discussed in the light of the digitalisation of urban geographies. Within this body of work, the focus is onto digitally augmented nature of our towns and cities (Graham, 2014), such as how a place, a monument, a shop, or an event is represented and defined online. Digital geography research often tackles problems concerning urban knowledge and information 
about space which are digitally mediated by any kind of technology, such as mapping, geo-localisation, and social media activities. The body of literature from digital geography has enriched our understanding of the relationship between digital platforms and their geography (Leszczynski, 2017). The significance of this strand is to be found in conceptual, methodological and empirical questions which address the 'digital turn' across geography's many sub-disciplines (Ash et al., 2018).

The question of networks in geography is not solely associated with accessibility to the territory in planning terms, but more about the 'findability' and the precision of algorithms to offer an on-demand match, geo-localised systems. Every kind of digital platform is designed to enhance a layer in which users, information, products and services meet, and-because the internet makes everything easy-platforms do it differently or faster. It is indisputable that global digital platforms such as Airbnb and Uber extract resources, through geolocalisation systems. For instance, when one is looking for a ride on the Uber app, the map geo-localises the user and shows that there are Uber drivers around you. In fact, these cars might be quite far from you; as a result, when one accepts the ride they vanish and the app displays the real geo-localisation of the selected driver.

Uber and Airbnb exemplify that the design of such platforms might severely disrupt the urban fabric and the labour market. As the internet-based services increasingly evolve from being a digital network that we log into, towards an assemblage of data and infrastructures that permeate all aspects of everyday life, the questions today revolve around what those changes mean for the ways that urban environments and communities are governed, planned, lived in, and challenged. Platform-based activities, ranging from Uber and Airbnb to grassroots community activism, are spatially concentrated in cities and build upon existing uneven geographies while feeding into wider urbanisation dynamics of economic development, environmental action, and everyday life (Evans, in press).

Graham's (2005, p. 571) work on software-sorted geographies claims that "spaces which escape the reach of regressive software-sorting systems do and will remain. A politics of transgressing, resisting, and even dismantling such increasingly inequitable systems is possible." If in the past, the digital divide was measured in terms of accessibility to the web, nowadays it is seen more as the capability to escape from the algorithmic regime. Conversely, the notion of a digital divide obscures the fact that what divides the included from the excluded is rarely access to the digital realm in itself: nominal access does not automatically lead to inclusion in the urban or access to services and goods. Isn't the digital divide expressed not in terms of access to technology vs. lack of access but how algorithms distribute access differentially among people who nominally have access? This seems at least as significant as the ability to escape.

\section{The Urban Digital Platform: An Operationalised Definition}

The proposed concept of UDP is positioned within the digital geography field and associates directly to the notion of platform urbanism. It complements the taxonomy (see Table 1) of global digital platforms, their corporate or profit-oriented characters, with another type of platform, operating exclusively in the urban realm and with other motives. Hence, the article further analyses how platforms for civic engagement and grassroots initiatives might tackle different social issues, providing tools to strengthen urban communities. Conversely, these initiatives might encounter limits and obstacles related to the control of the local state, the availability of financial resources, such as subsidies and grants, lack of participation, techno-biases, media literacy, and more. Notwithstanding, digital platforms do seem to have considerable implications, geographical as well as political. In this emerging research field, the article explores, from a geographical perspective, the relationship between digital platforms and urban conditions, starting from the theoretical stance on how the urban might affect digital platforms. In doing so, I analyse digital platforms which are explicitly embedded in the city. For instance, the whole array of projects analysed in the two platforms are utterly embedded in the two metropolitan areas of Milan and Amsterdam (see Figures 1 and 2).

From a political perspective implication, within a nonprofit oriented platform, networks are decentralised and data are open in terms of ownership. Data is not sold to other businesses, and information and knowledge exchange is not commodified through reviews or reputation systems, but rather they are collective goods. As Table 1 shows, UDPs are similar to co-ops which manage online platforms, in which the governance model shares the ownership of content and data are perceived as being a common good, not as a commodity for the platform itself (Scholz, 2016). What is different from the platform co-op model in the UDP is the role of the local government and the type of motive behind it. Co-ops can serve as protection for workers, such as Smart.Be which serves as a trade union for gig-economy riders. For instance, it is not based in cities, but it is a transnational entity, therefore it is not considered as part of UDPs. Besides, where UDPs are concerned, the role of urban governments cannot be underestimated. Whether they initiate and run platforms themselves or merely intervene in an ecosystem of grassroots initiatives (or both), the urban government is the single-most-important actor in shaping the local landscape of UDPs. Understanding the (dis)contents of their role (see the following interview quotes) should be a top priority for research at the intersection of digital geographies and the city. However, civic crowdfunding platforms and platforms that enhance grassroots efforts, such as Commonfare, require a closer look to capture whether or not the urban government is still crucial or if they can remain utterly self-organised. 
The tool-box that I propose conceptualises the UDP and makes the definition operationalised for empirical research: Firstly, a UDP operates at an urban scale and uses/redistributes local resources, it is $\mathrm{P} 2 \mathrm{P}$ in the provision of goods and services and offers citizen-based welfare solutions, it constitutes networks which are decentralised and whose data are open in terms of ownership (not sold to other businesses). Finally, it considers information and knowledge as collective goods, aiming to add social value and solidarity, and to contribute to public and private civic initiatives. In order to delve into these aspects and grasp the complex constellation of actors in UDPs, it is necessary to observe non-profit organisations more closely, political leaders, policymakers, as well as community activists and software developers where empirical analysis is needed. Secondly, a UDP might also need diverse actor constellations, such as technical providers and experts, and social and community entrepreneurs. The role of the local state is another important aspect. The next section explores these aspects in greater depth, supported by quotes and mapping of projects from my fieldwork based in Milan and Amsterdam.

\subsection{Instances of Urban Digital Platforms: Civic Crowdfunding \& Commonfare in Milan and Amsterdam}

Although there are efforts to enrich the discourse around platform urbanism, with 'vignettes,' such as the social media campaign around the hashtag \#deleteUber in the US, which are defined by Leszczynski (2020) as 'glitch,' there are no attempts to describe a platform which operates exclusively in the urban, which directly involves local resources and citizens. Therefore, I introduce the concept of UDP as a supplement to platform urbanism stressing the possibilities for non-capitalistic, P2P, and community-led platforms in global European cities, which might represent the same global capitalist accumulation from a political economy perspective but a different conception from US Western-based debates of the urban in terms of the morphology and social structure of a city.

Western geographical contexts and European global cities, such as Milan and Amsterdam, are prominent cities in which platform urbanism is unfolding. Within the two national contexts, Milan and Amsterdam are classified as two models which merged economic growth and global competition (ability to intercept global funds for urban development). Although this is not the main subject of the research, it is relevant to take this aspect into consideration. For example, if one looks at the real estate values, that is, the real estate prices in the two cities, you can see that they are directly proportional to their attractiveness. This dynamic is well illustrated by Hardt and Negri in Commonwealth: in terms of positive externalities (as economists call them) the two cities attract and concentrate innovative companies and prestigious universities, dynamic governments and efficient services in their metropolitan areas (Rossi, 2019). Furthermore, rare business services operate in these cities, such as tertiary services and financial hubs, as shown by the first global city analysts back in the 1990s (from Saskia Sassen to Peter Taylor). Corporate platforms, such as Airbnb and Uber, surf the length of the wave, exacerbating the existing inequalities that already exist in the two cities. From this point, there is the urge to point out that another subset of platforms exists: those that do not directly follow the same logic to attract global capital for urban development, but which aim to strengthen urban communities and (re)create social ties. However, this is not taken for granted.

A civic crowdfunding platform is a sub-type of crowdfunding through which citizens, often in collaboration with government, fund projects providing a community service, with civic and spatial aims (Davies, 2015; Gullino, Cerulli, Seetzen, \& Pacchi, 2018; Pais \& Pacchi, 2020). Commonfare is a welfare platform which offers complementary services, such as sharing information and knowledge and time-bank functions. For instance, one can offer an hour of babysitting in exchange for an hour of language teaching. Besides, Commonfare allows users and members of the platform to have a choice regarding privacy of their data. In these terms, they can be considered alternatives to the for-profit platforms which extract and sell their users' data at a global scale. UDPs are P2P in their type of provision of goods and services, and their orientation is not-for-profit. Main empirical findings of my research indicate that, instead of comparing private, public, and grassroot actors and bottom-up and top-down practices against each other, we need to look at the ways these hybridise within UDPs. The new proposal of UDPs is one way of enabling this. UDPs present themselves with a clear standard design, they are used to hold and distribute goods or services, diverse kind of resources, and even more importantly, social relationships. The local state is often engaged in the promotion of these platforms, as these interview quotes show:

Civic crowdfunding is a tool to fund ideas and projects from the bottom, aimed at social inclusion and cohesion....89\% of the projects promoted by the network and over 300,000 euros collected by web users show that today it is possible, thanks to crowdfunding, to speculate on different funding scenarios from public support to support social projects and new start-ups. Civic crowdfunding has been a sure bet. By co-financing those projects that are able to receive the first half of the initial funding from the bottom, we have supported more projects and we have been guided by the citizens in their choice. (Cristina Tajani, Milan Municipality, personal communication, October 2017, translation by the authors)

We come from a time of many hierarchical systems. The government and the organizations around it are 


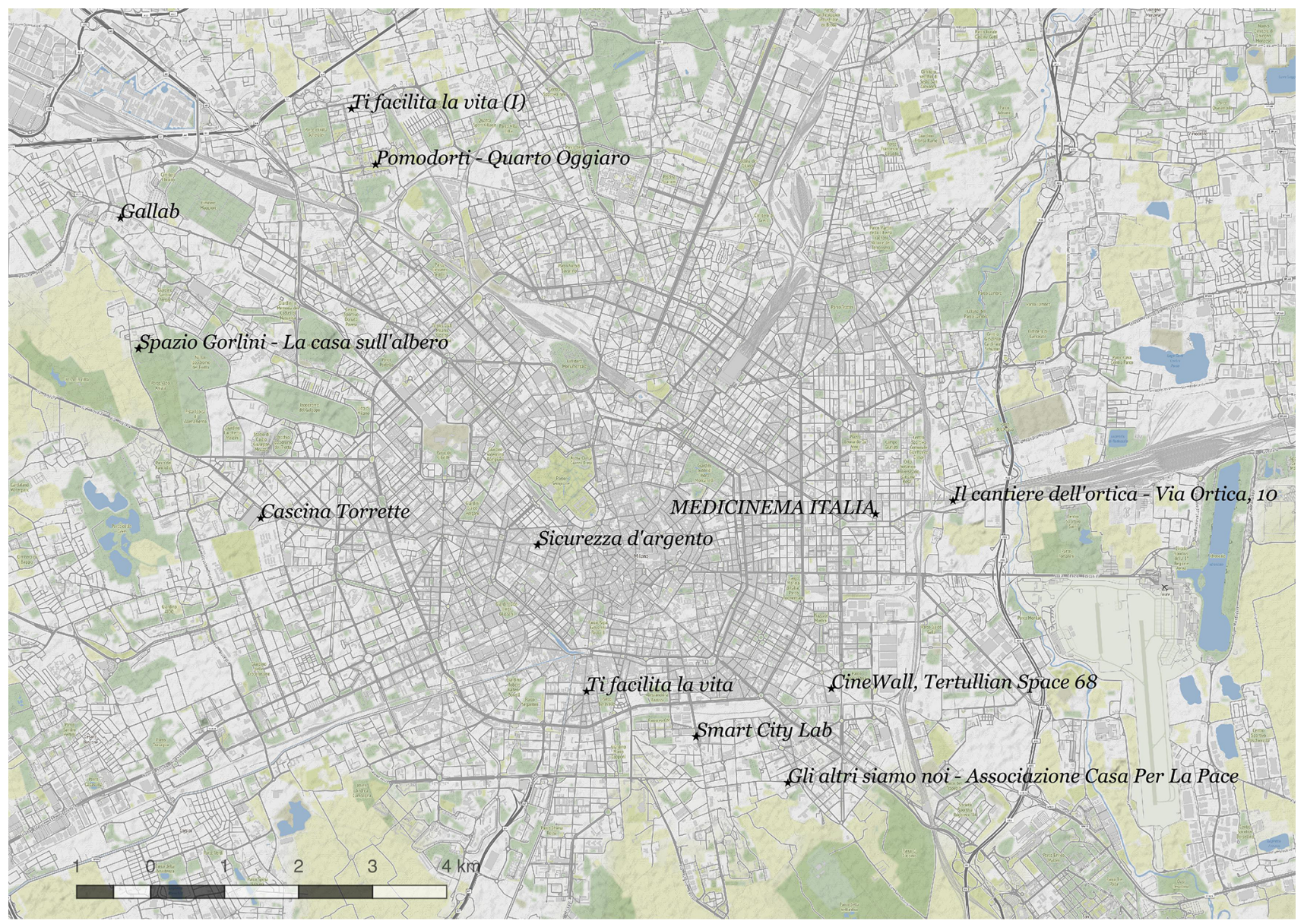

Figure 1. Civic crowdfunding realised projects in Milan, 2018. Source: Author.

very top-down organized and I see that people around me have the need to determine more about their own living environment. Platforms allow citizens to participate and foster bottom-up actions. (Juan-Carlos Goilo, Municipality of Amsterdam, personal communication, July 2018 , translation by the authors)

If civic crowdfunding and welfare platforms become important modes of coordination affecting cities, then the way access to these platforms is organised obviously has a political dimension. UDPs are crucial drivers of new socio-economic and local governance arrangements. In my findings, the small scale of the two examples of civic crowdfunding and welfare platforms such as Commonfare-all being within the metropolitan areas of Milan and Amsterdam-interfere with local arrangements in terms of the redistribution of local resources and oppose the extractive and exploitative nature of the corporate global platforms.

In the analysis, UDPs are defined by two main principles. The first is that these digital platforms do not pursue profit per se, rather, they are socially oriented. Revenues are reinvested in projects presented within the platform, just as we saw in the platform coop model mentioned earlier. The second concerns the internal organisation, which is open and decentralised, and, in particular the ownership of data: Users own their data, they know where it is stored, and they are involved in the decisions about how revenues are reinvested in services within urban communities. In contrast to corporate digital platforms, they do not sell the data they produce, nor do they extract value from users and exploit the commons for individual benefit. In other words, the techno-social configuration of platforms such as Commonfare allows users and members of the platform to have a choice regarding the privacy of their data. The techno-social configuration means something a bit different: Here, platforms do not 'have' techno-social configurations but become part of them through use (Johansen \& Fisker, 2020). In these terms, they can be considered to be alternatives to the for-profit platforms which extract and sell their users' data and operate at a global scale.

However, clearly formal requirements with regard to who is allowed to use the platform is an important dimension of access. Nevertheless, access is framed in many more often implicit ways. Besides the economic capital, such as a computer and Internet access, social and cultural capital will play a role as pre-conditions for being able to access cloud platforms. The skills needed or 'media literacy' to be effective on a platform might vary from web-design skills to using the appropriate language of the particular community of that platform (Graham, 


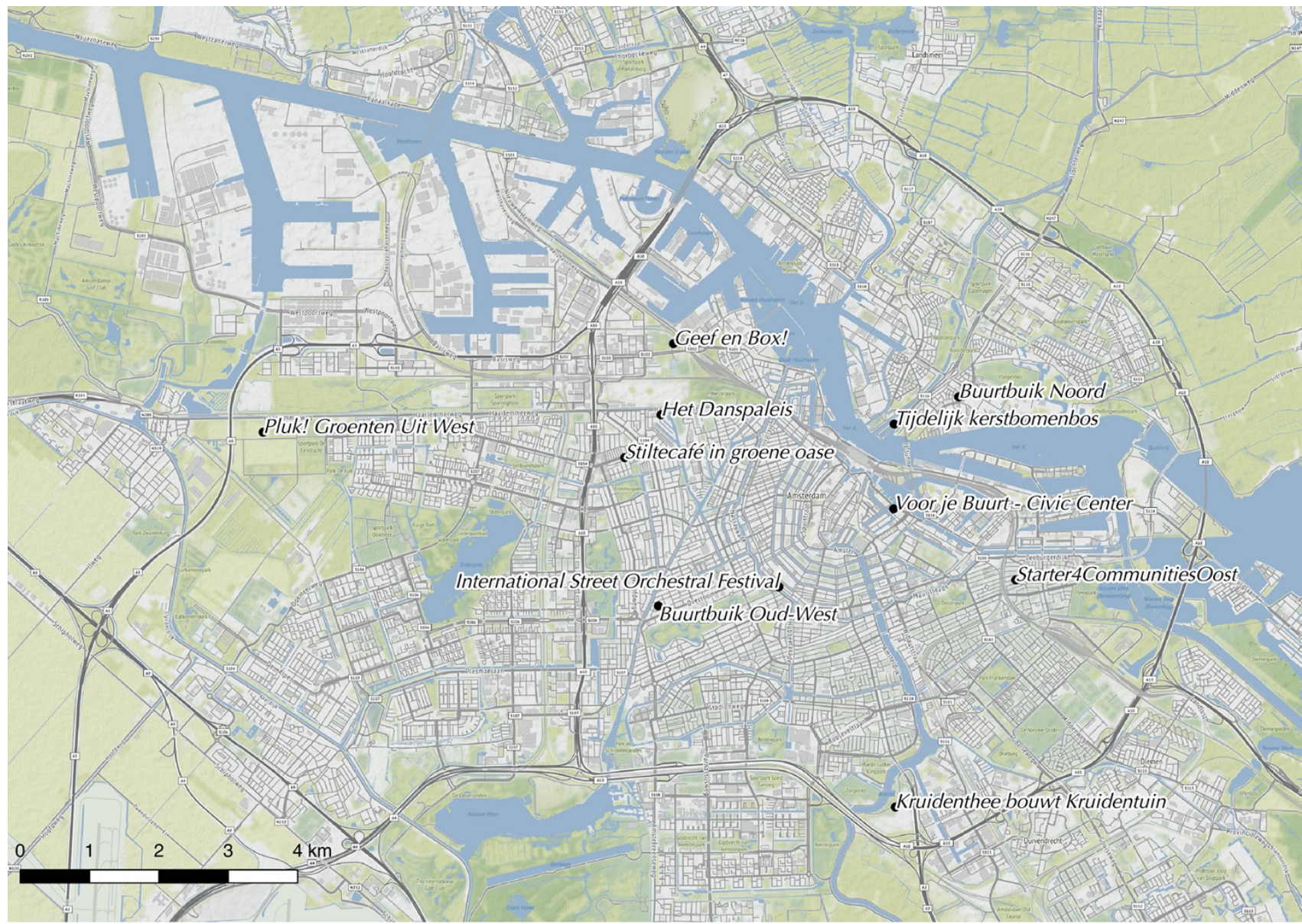

Figure 2. Civic crowdfunding realised projects in Amsterdam, 2018. Source: Author.

2014). As this quote from an anonymous civic crowdfunding project in Milan states:

It was very difficult for us running the campaign. We do not have so many digital skills, so the online part was an obstacle. We want to collect money offline, you know we have a lot of elderly people around here who do not know how to use the platform.

Yet, civic crowdfunding can be considered bottom-up in the proposal of projects and initiatives from citizens, but those bottom-up flows are often coordinated in a centralised system by the local state or a private technical provider. The risk is the creation of new uneven geographies or the exacerbation of existing those that already exist, as UDPs tend to mediate certain information and represent certain spaces and social groups over others. UDPs can also be not-profit yet still serve the platform urbanism logic of extracting value and selling it to third parties. What is crucial as a criterion is, for instance, the ability for users and members of the platform to have a choice regarding the privacy of their data (see example of Commonfare, where data are treated as common goods). The urban scale is also a potential space to reorganise communities and resources, which shows ambivalence and contradictions as much as the concept of urban com- mons does. As Enright and Rossi (2018, p. 35) claim the concept of urban commons shows contradictions that shed light "not only on multiple and even competing understandings and uses of the notion of the common(s), but also on the more general ambivalence of contemporary capitalism in its urban manifestation."

The main contradictions are in the re-appropriation of those resources. While the concept of platform urbanism is loose in describing the forms of urbanisation that any kind of platforms contribute to, UDPs are already framed and conceived as a contested terrain. They are the site of experimentation which might entail cooperative relations resulting in urban entrepreneurship and both P2P and market-oriented projects (which are not antithetical). The urban scale is not, and should not, be utterly founded on centralised mechanisms such as largescale projects or, as Bratton (2016) puts it, on 'the stack.' In the same vein, the concept of UDP serves as an analytical category to the contradictions that contemporary capitalism shows in its form of platform urbanism. In this ambivalence, UDPs rely on the challenge of different patterns of urban futures.

However, UDPs can enrich the digital urban theory which drawn both on the abstract level of the stack as a point of departure and the urban realm as essential pre-requisite to make those platform function. This is 
the main reason why UDPs are inherently urban: First, they rely on the urban condition, such as the density of social relations and physical proximity between users and material resources (e.g., built environment, amenities). Secondly, UDPs often require the intervention of the urban government (e.g., civic crowdfunding) or a third sector as in the case of Commonfare. Lastly, the output of UDPs enables a redistribution of local resources and common goods and services, resulting in an alternative production of space (Fisker, Chiappini, Pugalis, \& Bruzzese, 2018).

\section{4. 'The Stack' and Its 'City Layer'}

Elsewhere, digital platforms can also be understood as complex infrastructures. Media theorist Bratton (2016) refers to the 'stack,' a shorthand originating from programming work, as a fundamental layer of what he defines as planetary-scale computation based on cloudbased platforms. Following Bratton's reasoning, computational technologies such as smart grids, cloud platforms, smart cities, the Internet of Things, and automation, are defined as accidental megastructures. The stack is composed of six layers: earth, cloud, address, interface, city, and user. One of the most important elements for the conceptualisation of the UDP is the 'city layer':

It is [in the city layer] that The Stack becomes an apparatus of inhabitation. Global urban networks situate mobility and settlement, combining physical, informational and ecological infrastructures. These form different envelopes from which architecturally-based and software-based envelopes subdivide and enforce different rights of access and circulation. (Bratton, 2016, p. 129)

Simultaneously, it has to be noticed that UDPs, or platforms in general, rely on existing platforms. An app, for example, that is used as a P2P crowdfunding (or any non-profit oriented platform) still relies on: Google's Android or Apple's iPhone, the cellular network (T-Mobile, AT\&T), cloud platforms (Amazon) that the app connects to (which stores whatever central data is necessary), and internet infrastructure. In his terms, Bratton attempts to overcome the dualistic view of the relationship between technologies and physical space, and more precisely between virtual networks and territorial boundaries. He implies that those levels are now mutually constitutive elements of the city itself, as an extension of global digital infrastructure and the city layer brings up the importance of the relationship between territories and networks.

These theoretical axes are based on a potential new form of 'geopolitical sovereignty.' The link here to Lynch's (2020) piece on technological sovereignty activism in Barcelona is relevant to establish a clear connection with the city layer and the digital rights implied. This 'sovereignty' results in the management of networks which are not strictly linked to formally recognised territorial bound- aries, as a form of sovereignty which is at least partially decoupled from the nation-state, which instigates a dialectic view with Graham's (2005, p. 571) work on softwaresorted geographies and the concept of UDP.

\subsection{Platform Urbanism as a Proposition of a New Field of Study for the concept of Urban Digital Platforms}

The concept of 'platform urbanism' stems from the field of digital geography and urban governance studies and is gaining traction due to its ability to illustrate new dynamics and spatial outcomes of global digital platforms. Barns (2018, p. 23) defines platform urbanism as such: "[It] concerns the reshaping of city infrastructures and services through platform-driven business models." The dominant tendency of global digital platforms is to impose a top-down governance model which heavily affect important urban sectors, such as housing, mobility, and retail (Barns, 2015, 2019). In this notion, there is a certain emphasis on data-driven forms of urbanism and new constellations of platform governance, namely different alliances of technical experts, politicians and policymakers, citizens and businesses, as well as the fact that it gives precedence to big corporate actors mostly drawn on observations in the US and global cities (Barns, 2016). In these terms, cities are local markets for global distributors. To be so, these platforms are fuelled with local knowledge and therefore local data. Short term rental platforms and food delivery platforms exploit density, size, and associated physical proximities that characterise the urban agglomerations in which they operate. Recently, Leszczynski (2020, p. 201) enriches the initial definitional work by proposing a minor theory:

Platform urbanism as theorized from the minor via the glitch reveals it to be a highly contingent, indeterminate, and necessarily incomplete phenomenon where erratic/erroneous configurations of platforms and cities are both the result of, and open to opportunities for, tactical manoeuvres rooted in everyday digital praxes that remake, unmake, and make differently platform/city interfaces.

However, platform urbanism and UDPs are both inherently sticky in place, UDPs contribute to this broader urban phenomenon of platform urbanism. Thus, there are two sequential forces that come into play: density and proximity in the physical space for the critical mass, viz. urban communities, which along with the digital infrastructure, viz. the platform, work in tandem in the production of uneven and asymmetrical urban space, viz. diversity. In both cases, information and knowledge are targeted in a specific way, digital platforms list and direct users to specific locations in the city via extensive use of maps and geo-localises providers and users. They do benefit from these elements and in fact, they depend on them. Table 2 is an attempt to itemise different digital platforms and show the diverse output. 
Table 2. Itemisation. Source: Author.

\begin{tabular}{lll}
\hline & Ulatform Urbanism & \\
\hline & \multicolumn{1}{c}{$\begin{array}{c}\text { UDPs } \\
\text { (not-for-profit, grassroots) }\end{array}$} & \multicolumn{1}{c}{$\begin{array}{c}\text { Global Digital Platforms } \\
\text { (corporate/business) }\end{array}$} \\
\hline $\begin{array}{l}\text { Civic crowdfunding } \\
\text { (local state intervention) }\end{array}$ & $\begin{array}{l}\text { Commonfare } \\
\text { (i.e., mutual aid, tokens, self-organised) }\end{array}$ & $\begin{array}{l}\text { Airbnb } \\
\text { Deliveroo } \\
\text { Uber }\end{array}$ \\
$\begin{array}{l}\text { Output: Alternative, redistribution of local } \\
\text { resources and common goods and services }\end{array}$ & $\begin{array}{l}\text { Output: Platform Capitalism, extraction of values } \\
\text { values and exploitation of resources }\end{array}$ \\
\hline
\end{tabular}

While platform urbanism is a new field of study and broadly interrogates the platform-mediated urban condition (Rodgers \& Moore, 2018), the UDPs feature the novelty of the concept which emphasises the 'urban' as a battleground for alternative strategies. In the same vein of Fields, Bissell, and Macrorie (2020, p. 463), UDPs are a new concept for "geographers concerned with the digital urban interface are working to think about the potential for a counter-politics that is not rooted exclusively in resistance or antagonism." Finally, the article does not intend to set a false binary between platform urbanism and UDPs, rather as a continuum between these relevant concepts.

\section{Conclusion}

As a conclusion, UDPs such as Commonfare and examples of civic crowdfunding platforms are still certainly not perfect in terms of minority use with respect to global platforms. Yet they are very relevant in order to analyse whether or not they will rework on urban communities and existing inequalities and how they might be made to co-exist in mutually beneficial ways along with neighbourhood associations, solidarity, and social functions in the city. In the end, this is not only a juxtaposition between terms, I consider the advent of what I define as UDPs as a moment to reflect upon the current historical conjunction, and the potential social and collective actions that such platforms can support.

However, UDP are not necessarily forms of resistance. In the two cases analysed, civic crowdfunding still requires the intervention of the local state apparatus, insofar as it is often involved as a regulator or co-founder to develop local projects within the metropolitan areas of the two cities. During the Covid-19 pandemic, the Municipality of Amsterdam launched its own state-led solidarity platform, and in Milan they decided to open up another round of civic crowdfunding. Following empirical research, I observe that citizen-oriented practices promoted on UDPs often reproduce a certain unevenness in the distribution of goods and services, prioritizing certain areas of the city over others. While Commonfare represents an alternative, self-organised and autonomous UDP, the obstacles are still evident.
A future research agenda within this burgeoning field might interrogate how and in what way can something be truly non-profit/communal if at each underlying component in the stack, data is being extracted for profit? What communal possibilities exist despite the corporate reliance, the tendency toward data surveillance, and the ways in which each of them reinforce the non-communal aspects of society? How do UDPs create opportunities within these interstices for mundane tactics to escape the algorithms and go 'down the stack,' to co-opt and resist and counter the hegemonic discourse? Tokens and cooperative relations are potential incentives, but as you well know, it is not only about that.

\section{Acknowledgments}

A draft version of this article was presented in the Workshop "Urban Platforms and the Future City" held at the University of Manchester. I am very grateful for the feedback received at this event, particularly from John Stehlin, Sarah Barns, Dillon Mahmoudi, Desiree Fields, Agnieszka Leszczynski, and Niels van Doorn. I also thank the reviewers for their precious comments. The usual disclaimer applies.

\section{Conflict of Interests}

The author declares no conflict of interests.

\section{References}

Angelo, H., \& Wachsmuth, D. (2015). Urbanizing urban political ecology: A critique of methodological cityism. International Journal of Urban and Regional Research, 39(1), 16-27.

Artioli, F. (2018). Digital platforms and cities: A literature review for urban research (Cities Are Back in Town Working Papers 01/2018). Paris: Sciences Po Urban School.

Aschoff, N. (2015). The new prophets of capital. London: Verso.

Ash, J., Kitchin, R., \& Leszczynski, A. (2018). Digital turn, digital geographies? Progress in Human Geography, 42(1), 25-43. 
Barns, S. (2015). Platform cities: The politics and practices of data-driven urbanism. Paper presented at the Urban Studies Foundation Forum, University of Glasgow, Scotland.

Barns, S. (2016). Mine your data: Open data, digital strategies and entrepreneurial governance by code. Urban Geography, 37(4), 554-571.

Barns, S. (2018). Smart cities and urban data platforms: Designing interfaces for smart governance. City, Culture and Society, 12, 5-12.

Barns, S. (2019). Negotiating the platform pivot: From participatory digital ecosystems to infrastructures of everyday life. Geography Compass, 13(9). https://doi. org/10.1111/gec3.12464

Benkler, Y. (2006). The wealth of networks: How social production transforms markets and freedom. New Haven, CT: Yale University Press.

Botsman, R., \& Rogers, R. (2010). What's mine is yours: The rise of collaborative consumption. New York, NY: Harper Collins.

Bratton, B. H. (2016). The stack: On software and sovereignty. Cambridge, MA: MIT Press.

Brenner, N. (2004). New state spaces: Urban governance and the rescaling of statehood. Oxford: Oxford University Press.

Brenner, N., Marcuse, P., \& Mayer, M. (2009). Cities for people, not for profit. City, 13(2/3), 176-184.

Celata, F., Hendrickson, C. Y., \& Sanna, V. S. (2017). The sharing economy as community marketplace? Trust, reciprocity and belonging in peer-to-peer accommodation platforms. Cambridge Journal of Regions, Economy and Society, 10(2), 349-363.

Davies, R. (2015). Three provocations for civic crowdfunding. Information, Communication \& Society, 18(3), 342-355.

Enright, T., \& Rossi, U. (2018). Ambivalence of the urban commons. In K. Ward, A. E. G. Jonas, B. Miller, \& D. Wilson (Eds.), The Routledge handbook on spaces of urban politics (pp. 35-46). London: Routledge.

Evans, J. L. (in press). Urban platforms and the future city: Transformations in infrastructure, governance, knowledge, and everyday life. London: Routledge.

Fields, D., Bissell, D., \& Macrorie, R. (2020). Platform methods: Studying platform urbanism outside the black box- Urban Geography, 41(3), 462-468.

Fisker, J. K., Chiappini, L., Pugalis, L., \& Bruzzese, A. (2018). The production of alternative urban spaces: An international dialogue. London: Routledge.

Fisker, J. K., Chiappini, L., Pugalis, L., \& Bruzzese, A. (2019). Enabling urban alternatives. Singapore: Springer.

Frenken, K., \& Schor, J. (2017). Putting the sharing economy into perspective. Environmental Innovation and Societal Transitions, 23, 3-10.

Gillespie, T. (2010). The politics of 'platforms.' New Media \& Society, 12(3), 347-364.

Gillespie, T. (2018). Custodians of the internet: Platforms, content moderation, and the hidden decisions that shape social media. New Haven, CT: Yale University
Press.

Graham, S. D. (2005). Software-sorted geographies. Progress in Human Geography, 29(5), 562-580.

Graham, M. (2014). Internet geographies: Data shadows and digital divisions of labour. In M. Graham \& W. Dutton (Eds.), The internet and society (pp. 99-116). Oxford: Oxford University Press.

Gramsci, A. (1994). Gramsci: Pre-prison writings. Cambridge: Cambridge University Press.

Greenfield, A. (2017). Radical technologies: The design of everyday life. Brooklyn, NY: Verso Books.

Gullino, S., Cerulli, C., Seetzen, H., \& Pacchi, C. (2018). Citizen-led micro-regeneration. In J. K. Fisker, L. Chiappini, L. Pugalis, \& A. Bruzzese (Eds.), The production of alternative urban spaces: An international dialogue (pp. 210-226). London: Routledge.

Hine, C. (2017). From virtual ethnography to the embedded, embodied, everyday internet. In L. Hjorth, H. Horst, A. Galloway, \& G. Bell (Eds.), The Routledge companion to digital ethnography (pp. 47-54). London: Routledge.

Johansen, P. H., \& Fisker, J. K. (2020). Technosocial configurations for sociability in rural Denmark. Journal of Rural Studies, 78, 115-122.

Karatzogianni, A., \& Matthews, J. (2018). Platform ideologies: Ideological production in digital intermediation. Platforms and structural effectivity in the "sharing economy." Television and New Media. Advance online publication. https://doi.org/10.1177 \%2F1527476418808029

Kitchin, R. (2019). Governance. In J. Ash, R. Kitchin, \& A. Leszczynski (Eds.), Digital geographies (pp. 225-238). Los Angeles, CA: Sage.

Kitchin, R., \& Dodge, M. (2011). Code/space: Software and everyday life. London and Cambridge, MA: MIT Press.

Kohn, M. (2016). The death and life of the urban commonwealth. Oxford: Oxford University Press.

Langley, P., \& Leyshon, A. (2017). Platform capitalism: The intermediation and capitalisation of digital economic circulation. Finance and Society, 3(1), 11-31.

Leszczynski, A. (2017). Digital methods I: Wicked tensions. Progress in Human Geography, 42(3), 473-481.

Leszczynski, A. (2020). Glitchy vignettes of platform urbanism. EPD: Society and Space, 38(2), 189-208.

Lynch, C. R. (2020). Contesting digital futures: Urban politics, alternative economies, and the movement for technological sovereignty in Barcelona. Antipode, 52(3), 660-680.

Merrifield, A. (2014). The entrepreneur's new clothes. Geografiska Annaler B: Human Geography, 96(4), 389-391.

Moore, S., \& Scott, S. (2018). CFP AAG 2018: Platform urbanism. Publicly Sited. Retrieved from http://www. publiclysited.com/cfp-aag-2018-platform-urbanism

Mos, E. (2020). Digital platforms and the re-organization of solidarity. Platform Labor. Retrieved from 
https://platformlabor.net/blog/digital-platformsand-the-reorganization-of-solidarity

Painter, J. (2010). Rethinking territory. Antipode, 42(5), 1090-1118.

Pais, I., \& Pacchi, C. (2020). Civic crowdfunding in Milan, between grassroots actors and policy opportunities. In O. Gajda, D. Marom, \& T. Wright (Eds.), CrowdAsset: Crowdfunding for policymakers (pp. 257-273). Hackensack, NJ: World Scientific Pub.

Pasquale, F. (2015). The black box society: The secret algorithms that control money and information. Cambridge, MA: Harvard University Press.

Pasquale, F. (2018). From territorial to functional sovereignty: The case of Amazon. openDemocracy. Retrieved from https://www.opendemocracy.net/ en/digitaliberties/from-territorial-to-functionalsovereignty-case-of-amazon

Purcell, M. (2008). Recapturing democracy. New York, NY: Routledge.

Richardson, L. (2019). Sharing economy. In J. Ash, R. Kitchin, \& A. Leszczynski (Eds.), Digital geographies (pp. 200-210). Los Angeles, CA: Sage.

Rodgers, S., \& Moore, S. (2018). Platform urbanism: An introduction. Mediapolis, 41(3). Retrieved from https://www.mediapolisjournal.com/2018/10/ platform-urbanism-an-introduction

Rose, G., Raghuram, P., Watson, S., \& Wigley, E. (2020). Platform urbanism, smartphone applications and valuing data in a smart city. Royal Geographical
Society. Advance online publication. https://doi.org/ 10.1111/tran. 12400

Rossi, U. (2019). The common-seekers: Capturing and reclaiming value in the platform metropolis. Environment and Planning C: Politics and Space, 37(8), 1418-1433.

Scholz, T. (2016). Platform cooperativism. Challenging the corporate sharing economy. New York, NY: Rosa Luxemburg Foundation.

Scott, A., \& Storper, M. (2015). The nature of cities: The scope and limits of urban theory. International Journal of Urban and Regional Research, 39(1), 1-16.

Srnicek, N. (2017). Platform capitalism. London: John Wiley \& Sons.

Törnberg, P., \& Chiappini, L. (2020). Selling black places on Airbnb: Colonial discourse and the marketing of black communities in New York City. Environment and Planning A: Economy and Space, 52(3), 553-572. https://doi.org/10.1177/0308518X19886321

van Dijck, J., Poell, T., \& de Waal, M. (2018). The platform society: Public values in a connective world. Oxford: Oxford University Press.

van Doorn, N. (2019). A new institution on the block: On platform urbanism and Airbnb citizenship. New Media \& Society. https://doi.org/10.1177/ 1461444819884377

Woodcock, J., \& Graham, M. (2019). The gig economy: A critical introduction. Cambridge: Polity.

\section{About the Author}

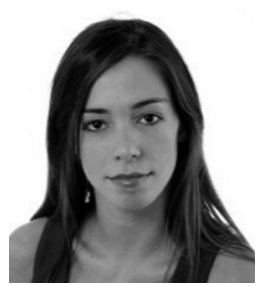

Letizia Chiappini is a PhD candidate in Urban Studies (UrbEur Doctorate) at the University of Milan-Bicocca and at the University of Amsterdam (joint doctorate). Her research interests revolve around urban transformations and societal changes under capitalism. In her PhD research, she proposes the concept of 'urban digital platform' to analyse digital platforms oriented to support grassroots initiatives and citizen engagement, such as civic crowdfunding and complementary welfare platforms. It is a comparative analysis based on four years of fieldwork in Milan and Amsterdam. 